Journal of Engineering and Applied Sciences 7 (5): 372-378, 2012

ISSN: 1816-949X

(C) Medwell Journals, 2012

\title{
Monitoring of Corrosion of Aeromonas eucrenohila in the First Steps of Biofilm Formation on Nickel
}

\author{
${ }^{1}$ A.P.F. Tabrizi, ${ }^{1,2}$ H. Nazir, ${ }^{1}$ N.O. San and ${ }^{3}$ G. Donmez \\ ${ }^{1}$ Institute of Biotechnology, ${ }^{2}$ Department of Chemistry, Faculty of Science, \\ ${ }^{3}$ Department of Biology, Faculty of Science, Ankara University, 06100 Tandogan, Ankara, Turkey
}

\begin{abstract}
The microbial corrosion behaviour of $\mathrm{Ni}$ in nutrient broth and in the presence of Aeromonas eucrenophila, isolated from water treatment system has been studied using electrochemical techniques such as Open Circuit Potential (OCP), Quartz Crystal Microbalance (QCM), Tafel and Electrochemical Impedance Spectroscopy (EIS). The electrochemical results declare the 1st stage of biofilm formation of A. eucrenophila shows pseudoprotection effect while increase the time accelerates the corrosion of nickel by increasing the surface inhomogeneity. The formation of the biofilm and the roughness of the nickel surface were characterized using Scanning Electron Microscopy (SEM) with Energy Dispersive X-ray (EDX) analysis and FT-IR spectroscopy. In addition, the $\mathrm{pH}$ values of the medium did not change throughout the experiment, however after immersion in the medium with bacterium the $\mathrm{pH}$ value decreased to acidic value and caused corrosion.
\end{abstract}

Key words: EIS, nickel coatings, microbiological corrosion, polarization, SEM, FTIR

\section{INTRODUCTION}

Nickel is an important metal to industry due to a wide variety of manufacturing applications. Nickel due to resistance to corrosion along with its electrical and thermal properties is used as a coating material particularly iron-based steels substrates. The industrial applications of the nickel also makes it a favorite subject of study for researchers. The investigations on the corrosion of the nickel in different environments has been reported already (Jouen et al., 2004; Abd El-Haleem and Abd El-Wanees, 2011; Abdallah and El-Etre, 2003). In these studies, it is stated that the resistance of nickel to the corrosion on the surface is due to passive film of the Nickel Oxide $(\mathrm{NiO}) /$ hydroxide $\left[\mathrm{Ni}(\mathrm{OH})_{2}\right]$. On the other hand in the corrosion process, the bacterial adhesion and biofilm formation is referred to as a general reason of corrosion (Teng et al., 2008; Hori and Matsumoto, 2010). The deterioration of metal due to microbial activity is termed biocorrosion or Microbially Influenced Corrosion (MIC) (Gaylarde, 1992; Videla, 2001). Bacteria attach to surfaces and then replicate and produce exopolymers (EPS) forming a cohesive structure on the surface known as a biofilm (Costerton et al., 1995; Little et al., 1996, 1999). EPS are primarily composed of polysaccharides, uronic acid sugars and proteins containing functional groups such as carboxylic acid and amino acid groups which could be acidic and capable of binding metal ions (Geesey et al., 1988). Thus, EPS can affect the electrochemical characteristics of metal surface and play an important role in the corrosion of metal (Roe et al., 1996).

The purpose of this study is the comparison and determination of corrosion caused by bacterial proliferation and EPS excretion in inoculated A. eucrenophila and nutrient broth media.

\section{MATERIALS AND METHODS}

The bacterium used in this study was A. eucrenophila obtained from Culture Collection of Biotechnology Research Laboratories, Biology Department, Ankara University, Turkey (NCBI Gen Bank Accession No. GQ466170 (http://www.ncbi.nlm.nih.gov)). All experiments were done with freshly supplied bacterium.

Electrochemical measurements were carried out in a conventional three-electrode cell with lugging capillarly with a capacity of $10 \mathrm{~mL}$. The polarization curves and EIS were measured using CompactStat Potentiostat (IviumStat, The Netherlands). The EIS measurements were carried out at $5 \mathrm{mV}$ applied voltage at sinusoidal wave in the frequency range $20 \mathrm{kHz}$ to $50 \mathrm{mHz}$. The EIS results obtained were modeled and simulated using ZView software (Version 3.3b). All of the investigations were done at the end of $5 \mathrm{~h}$ which is enough time for production of biofilm. The Tafel curves were obtained by scanning from potential towards anodically and

Corresponding Author: H. Nazir, Institute of Biotechnology, Ankara University, 06100 Tandogan, Ankara, Turkey 
cathodically at a scan rate of $1 \mathrm{mV} \mathrm{sec}^{-1}$. The QCM measurements were carried out in a Model 400A timeresolved quartz crystal microbalance $(\mathrm{CH}$ Instruments, USA) linked to a computer equipped with electrochemistry software (CHI400A). In the QCM experiments, AT-cut gold quartz crystal (CHI125A) was used as a working electrode and nickel was deposited on this gold surface of the crystal. Surface area of a gold crystal was $0.204 \mathrm{~cm}^{2}$ and its nominal resonant frequency was $7.995 \mathrm{mHz}$. In other electrochemical experiments (OCP, Tafel and EIS) ST-42 carbon steel with a surface area of $0.204 \mathrm{~cm}^{2}$ was used as a working electrode. The $\mathrm{Ag} / \mathrm{AgCl}$ (sat. $\mathrm{KCl}$ ) electrode (CHI111) was used as the easy the lateral and vertical reference electrode and a platinum wire (CHI115) was used as counter electrode for all experiments.

$\mathrm{Ni}$ coating was electrodeposited from the mixture of $\mathrm{NiSO}_{4} .7 \mathrm{H}_{2} \mathrm{O}\left(280 \mathrm{~g} \mathrm{~L}^{-1}\right), \mathrm{NiCl}_{2} \cdot 6 \mathrm{H}_{2} \mathrm{O}\left(23.7 \mathrm{~g} \mathrm{~L}^{-1}\right)$ and $\mathrm{H}_{3} \mathrm{BO}_{3}$ $\left(31 \mathrm{~g} \mathrm{~L}^{-1}\right)$. All reagents were analytical grade from Merck. The same thickness for all coatings, electrodeposition was performed chronoamperometrically and applied a potential range of $(-0.4 \mathrm{~V})-(-0.9 \mathrm{~V})(\mathrm{vs} . \mathrm{Ag} / \mathrm{AgCl})$ to the electrolys is system for $200 \mathrm{sec}$ during the nickel coatings, respectively. Using the bathing solutions explained, the $\mathrm{Ni}$ thin films was electroplated with a thickness of approximately $100 \mathrm{~nm}$ on one side of the quartz crystal electrodes. Data acquisition software was used to record the mass change. Frequency change $(\Delta h z)$ was converted into the mass change $(\Delta \mathrm{m})$ using the Sauerbrey (1959)'s equation.

At the end of electrochemical experiments, nickel coating discs in medium and a medium containing bacterium were used for SEM under stationary conditions. At the end of experiments, the discs were taken from medium, rinsed with deionized water and dried under a stream of nitrogen gas. Surface morphology was analyzed with a Scanning Electron Microscope (JEOL JSM-7000F Field Emission SEM-EDAX).

Disc surface containing biofilm were analyzed using FT-IR spectroscopy through an Affinity-1 model equipped with ATR (4000-650 $\mathrm{cm}^{-1}$ ) (Shimadzu, Japan). Measurements of the nickel coated steel disc were made in $20 \mathrm{~mL}$ glass flask containing $4 \mathrm{~mL} \mathrm{~N}$ broth medium inoculated with $10 \mu \mathrm{L}$ bacterium. At the end of $5 \mathrm{~h}$, discs surface were scraped in the sample holder and then analyzed.

To investigate the changes in the $\mathrm{pH}$ level, corrosion of $\mathrm{Ni}$ coatings experiments were carried out into laboratory conditions. To compare the influence of the bacterium, $\mathrm{pH}$ changes in sterile medium and medium containing bacterium were measured $300 \mathrm{~min}$ after inoculation.

\section{RESULTS AND DISCUSSION}

The corrosion potential of nickel electrodes that exposure in medium and inoculated medium has been shown in Fig. 1. The nickel's corrosion potential value $\left(\mathrm{E}_{\text {ocp }}\right)$ in bacterium $\{-0.297 \mathrm{~V}$ (vs. $\left.\mathrm{Ag} / \mathrm{AgCl})\right\}$ is lower than inmedium $\{-0.277 \mathrm{~V}$ (vs. $\mathrm{Ag} / \mathrm{AgCl})\}$ approximately $20 \mathrm{mV}$. Figure 1 shows that there is a different tendency in corrosion potential curves between electrodes that exposure to medium and bacterium. Also, the corrosion potential in $A$. eucrenophila media initially continues toward positive values while after approximately $1 \mathrm{~h}$ potential was fallen down to more negative values. This situation depends on the bacterium activation and biofilm formation on electrode surface (El-Taib Heakal et al., 2010). In the other hand in electrochemical controllable aqueous solutions, QCM is able to detect the mass changes of electrode surfaces in the range of $\mathrm{ng} / \mathrm{cm}$ (Wang et al., 2006). Figure 2 shows the mass change of electrode surface in the exposure time period. At the end of experiment procedure, the mass lose of electrode surface in medium is $-1.30 \mu \mathrm{g}$ while it is $-1.78 \mu \mathrm{g}$ in bacterium. It can be clearly expressed that the bacterium media is more corrosive than medium.

The polarization curves of nickel electrodes in medium and bacterium for $60 \mathrm{~min}$ and $5 \mathrm{~h}$ time periods are shown in Fig. 3. The electrochemical corrosion parameters (corrosion potential ( $\left.\mathrm{E}_{\text {corr }}\right)$; corrosion current (i ) corrosion current density $\left(\mathrm{I}_{\text {corr }}\right)$; anodic tafel slope $\left(\beta_{\mathrm{a}}\right)$; cathodic tafel slope $\left(\beta_{c}\right)$ and polarization resistance $\left(R_{p}\right)$ that obtain from tafel curves are shown in Table 1. After being immersed in medium for $5 \mathrm{~h}$, the corrosion potential of Ni was observed to be $-0.28 \mathrm{~V}$ (vs. $\mathrm{Ag} / \mathrm{AgCl}$ ). However, the corrosion potential of $\mathrm{Ni}$ in the medium inoculated with the bacterium for $60 \mathrm{~min}$, shifting to anodic site,

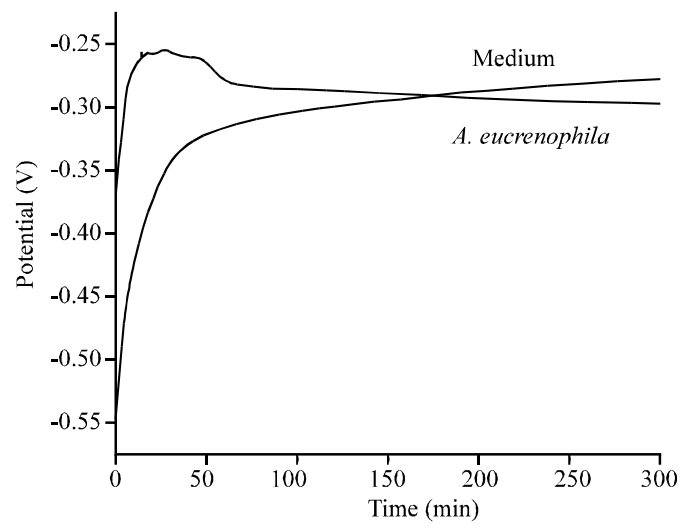

Fig. 1: Variation of OCP of nickel electrodes immersed in sterile medium and $A$. eucrenophila inoculated medium 


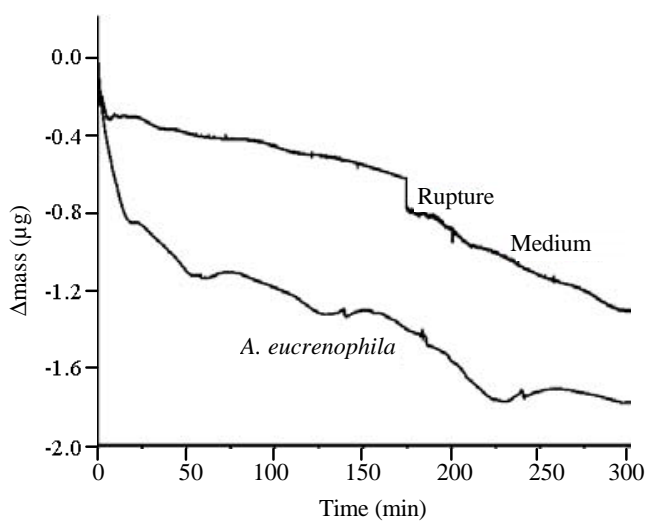

Fig. 2: Time dependence of mass changes of nickel electrodes in sterile medium and A. eucrenophila inoculated medium at the room temperature

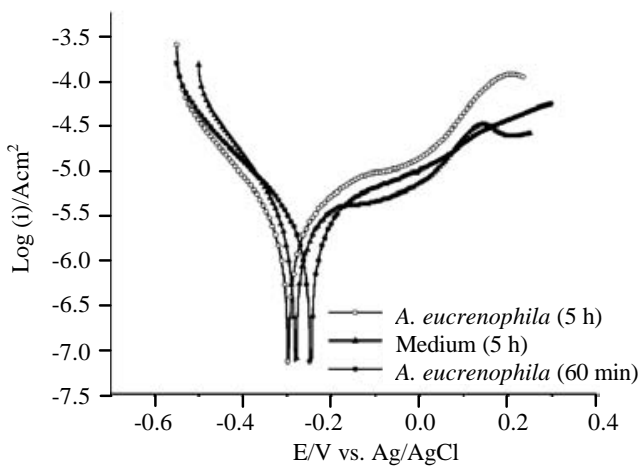

Fig. 3: The polarization curves of nickel electrodes

$-0.25 \mathrm{~V}$ (vs. $\mathrm{Ag} / \mathrm{AgCl}$ ) means the rate of corrosion has decreased. Thus, the positive shift of $\beta$ a values shows that electron transfer from anodic side is difficult. Nontheless due to the bacterial activation and the rapid increasing in the amount of oxygen on the surface and also because of Extracellular Polymeric Substance (EPS) inhibition efficiency (Little et al., 1996; Zuo et al., 2005), this protection is pseudoprotection. However, dependent on incubation time, SEM images shows roughness, pits and lateral and vertical crevices on the surface.

This new surface caused increments of corrosion current and corrosion current density (Cetin and Aksu, 2009). At the end of $5 \mathrm{~h}$, the corrosion potential of the biofilm formation shifted to cathodic site, $-0.30 \mathrm{~V}$ (vs. $\mathrm{Ag} / \mathrm{AgCl}$ ). In addition, increase of corrosion current and corrosion current densities with an increase in incubation time which means the increased rate of corrosion and the pitted and creviced surface. Therefore, system is sensitive to microbial corrosion. EIS results are agreement with Tafel results.

Figure 4 shows the EIS and equivalent circuit used in the analysis of $\mathrm{Ni}$ in both the medium and in the
Table 1: The corrosion parameters determined from the Tafel plots for nickel in the medium and $A$ e eucrenophila inoculated medium

\begin{tabular}{llll}
\hline & Medium & \multicolumn{2}{c}{ After inoculation } \\
& $(5 \mathrm{~h})$ & $60 \mathrm{~min}$ & $5 \mathrm{~h}$ \\
\hline Parameters & -0.28 & -0.25 & -0.30 \\
$\mathrm{E}_{\text {corr }} \mathrm{V} \mathrm{vs.} \mathrm{Ag} / \mathrm{AgCl}$ & 1.04 & 1.68 & 2.04 \\
$\mathrm{i}_{\text {corr }}(\mu \mathrm{A})$ & 4.92 & 8.24 & 10.01 \\
$\mathrm{I}_{\text {cor }}\left(\mu \mathrm{A} \mathrm{cm} \mathrm{cm}^{-2}\right)$ & 0.47 & 0.51 & 0.62 \\
Anodic tafel slope $\beta_{\mathrm{a}}(\mathrm{V} / \mathrm{dec})$ & 0.13 & 0.25 & 0.25 \\
Cathodic tafel slope $\beta_{\mathrm{c}}(\mathrm{V} / \mathrm{dec})$ & 96138 & 93198 & 80099 \\
$\mathrm{R}_{\mathrm{p}}\left(\Omega \mathrm{cm}^{2}\right)$ & 3.28 & 5.50 & 6.68 \\
Corrosion rate $\left(\mu \mathrm{m} \mathrm{year}^{-1}\right)$ & & & \\
\hline
\end{tabular}

Table 2: Electrochemical impedance parameters of the nickel in the medium and $A$ encrenophila inoculated medium

\begin{tabular}{lrrr}
\hline & & \multicolumn{2}{c}{ After inoculation } \\
& Medium & -1 & \multicolumn{1}{c}{ - } \\
& $(5 \mathrm{~h})$ & $60 \mathrm{~min}$ & \multicolumn{1}{c}{$5 \mathrm{~h}$} \\
\hline $\mathrm{R}_{\mathrm{s}}\left(\Omega \mathrm{cm}^{2}\right)$ & 915.20 & 1571.00 & 1196.00 \\
$\mathrm{R}_{\mathrm{ct}}$ & 103893.72 & 152076.40 & 48382.60 \\
$\mathrm{Q}_{\mathrm{dl}} \times 10^{-5}\left(\Omega^{-1} \mathrm{~cm}^{-2}\right)$ & 8.49 & 4.48 & 10.14 \\
$\eta$ & 0.86 & 0.87 & 0.83 \\
\hline
\end{tabular}

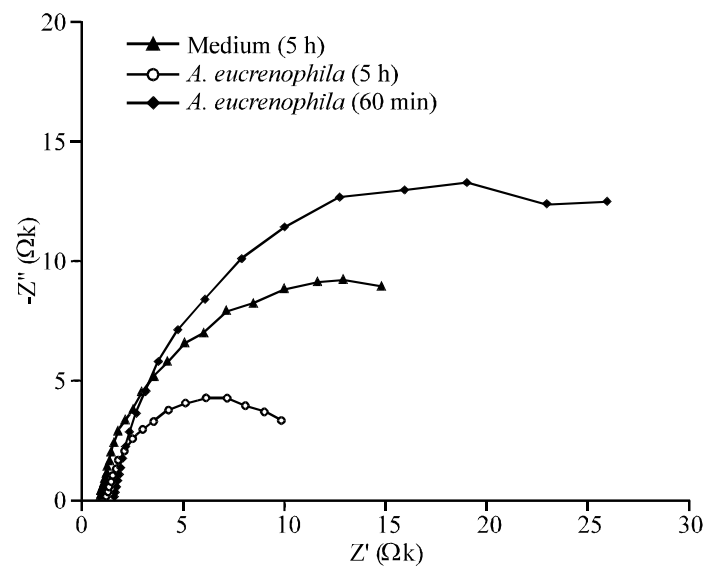

Fig. 4: The EIS of nickel in the sterile medium and A. eucrenophila inoculated medium

inoculated medium. For all experiments, before the measurements of EIS, cell potential and the cell current as a function of time due to biofilm formation were measured. The lowest and the highest values of $i_{\text {cell }}$ are 0.23 and $0.68 \mu \mathrm{A}$. When IR drop was calculated according to solution resistance values in Table 2, the IR drop was obtained 0.28-0.81 mA for nickel specimens. So, the EIS measurements were not corrected for IR biofilm drop. The Nyquist capacitive curves (Fig. 4) show a semi circular graphic on the way to high and low frequency. Also, the diameter of the impedance loops increased for $60 \mathrm{~min}$ then decreased for $5 \mathrm{~h}$ according to medium impedance loop. This pattern reveal a decrease in the rate of corrosion due to formation of a protective oxide layer and then with increasing the time shows a rise in the rate of corrosion. Figure 5 shows the respective magnitude and phase angle Bode plots. The magnitude plots give affirmative results for the Nyquist plots. Furthermore, the phase angle plots 


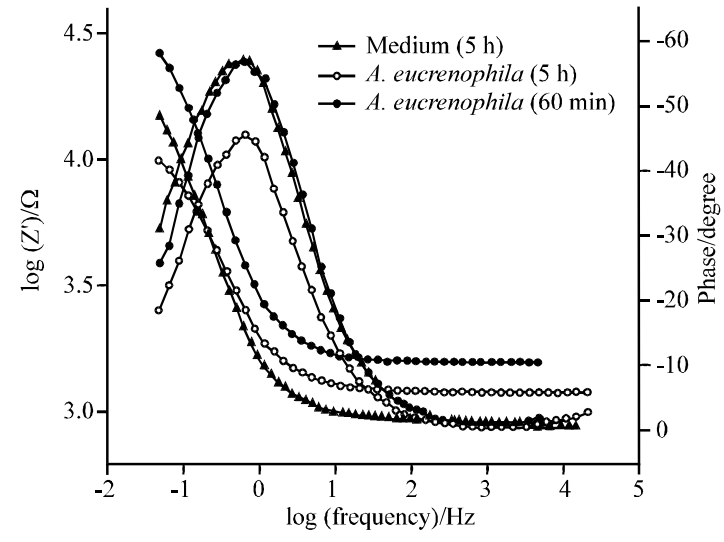

Fig. 5: The magnitude and phase angle Bode plots of nickel electrodes in sterile medium and A. eucrenophila inoculated medium

show one peak maximum at low frequency which derive from the Electrical Double Layer (EDL). As seen from Fig. 5, the peak maxima decrease from $\sim 57^{\circ}$ to $\sim 45^{\circ}$ with time beginin to $5 \mathrm{~h}$ refers to an increase in the corrosion rate. On the other hand, no phase shift was observed in the Bode diagrams. Therefore, the equivalent circuit includes one time constants. Figure 6 shows the physical structure of the surface film on the nickel specimens and their corresponding equivalent circuit (Yuan et al., 2007) which can be satisfactorily used for fitting the impedance data. Furthermore, it is significant to point out that the heterogeneous biofilm produced by A. eucrenophila on the nickel surface probably gives another peak. However, it was difficult to detect because the development of the biofilm is a dynamic process accompanied by the continuous attachment, growth and detachment on the solid metal surface (Yuan et al., 2007; Franklin et al., 2000). The obtained fitting electrochemical parameters are shown in Table 2. In the circuit, $R_{s}$ is the resistance of solution, $R_{c t}$ is the charge transfer resistance. $Q_{d l}$ is the Constant Phase Element (CPE) of the electric double layer. $\mathrm{CPE}$ is used due to the microscopic roughness of a surface and the center of the capacitive semicircle is below the real axis. $\eta$ is defined as the CPE power and the value of $\eta$ being less than one indicate an imperfect capacitor (Cetin and Aksu, 2009) and can be assumed as the measure of the surface inhomogeneity. At the end of exposured time in the inoculated medium with bacterium, the decreasing tendency of $\eta$ factor shows an increase in the solid surface roughening. As shown in Table $2, \mathrm{R}_{\mathrm{ct}}$ dramatically decreases with time in the inoculated medium and according to sterile medium indicates an increase in the corrosion rate of the $A$. eucrenophila cells and EPS on the nickel surface effected the kinetic process of the oxide film formation

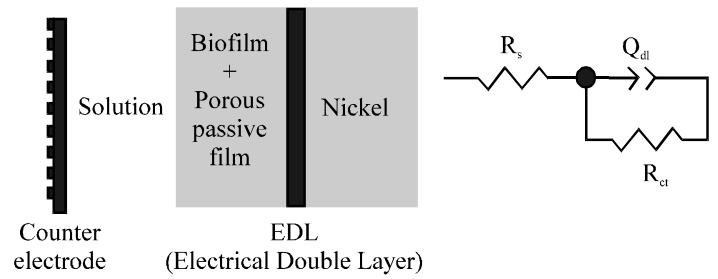

Fig. 6: The equivalent circuit of nickel in the sterile medium and A. eucrenophila inoculated medium

Table 3: Relative compositions of model constituents

\begin{tabular}{lcl}
\hline Components & Wave number $\left(\mathrm{cm}^{-1}\right)$ & Band assignment \\
\hline Hydrocarbons & 3279 & $\mathrm{O}-\mathrm{H}$ stretch \\
& 2920 & $\mathrm{CH}_{2}$ asymetric stretch \\
& 2848 & $\mathrm{CH}_{2}$ symetric stretch \\
Proteins & 1736,1639 & $\mathrm{C}=\mathrm{O}$ of amide I \\
& 1544 & $\mathrm{C}-\mathrm{N}$ of amide II \\
Polysaccharides & 1386 & $\mathrm{C}-\mathrm{O}$ from carboxylic acid \\
& 1230 & $\mathrm{P}=\mathrm{O}$ \\
& 1072 & $\mathrm{C}-\mathrm{O}, \mathrm{C}-\mathrm{O}-\mathrm{C}$ stretch \\
& & from polysaccharides \\
\hline
\end{tabular}

or to make easy the lateral and vertical deformation of the oxide film. The existing of biofilms on the metal surface has been widely acclaimed that the surface film loss the passivity, became more inhomogeneous and posed no barrier to the diffusion of active ions and product ions (Yuan et al., 2007; Caldwell et al., 1992; Videla, 2001; Valcarce et al., 2005).

Figure 7 shows the SEM images and EDX results of the $\mathrm{Ni}$ disc surfaces immersed in the medium and inoculated medium with bacterium for $5 \mathrm{~h}$ exposure. As shown in Fig. 7b, the surfaces of $\mathrm{Ni}$ specimens were partially covered with clusters of microbial cells, EPS and metabolism products. In addition in Fig. $7 \mathrm{~b}$ magnified $\times 4000$ SEM micrograph, more pitting and crevice corrosion were observed on the surface of the inoculated medium than on the surface of the medium (Fig. 7a, magnified $\times 4000$ ). EDX was used for elemental analysis of some typical areas on the surface of the nickel specimens. The result of the SEM analyze, the oxide percentage of the nickel surface in the medium was $1.02 \%$ (Fig. 7a) whereas the nickel in the bacterium was $2.90 \%$ (Fig. 7b). This result shows that $A$. eucrenophila caused the increase in the oxide percentage due to aerobic respiration.

Figure 8 shows the FT-IR spectrum of biofilm and EPS formed at the end of exposured time. The peak assignments are shown in Table 3. Possible groups located in biofilm with EPS structure are polysaccharides, proteins (amides) and hydrocarbons. Presence of $\mathrm{OH}$ groups is indicated by their stretching modes at $3279 \mathrm{~cm}^{-1}$. The peaks at 2920 and $2848 \mathrm{~cm}^{-1}$ are due to aliphatic $\mathrm{CH}$ and $\mathrm{CH}_{2}$ stretching modes. In the case of $\mathrm{C}=\mathrm{O}(\operatorname{amid} \mathrm{I})$ and $\mathrm{C}-\mathrm{N}(\mathrm{amid} \mathrm{I})$, two peaks were observed at 1639 and $1544 \mathrm{~cm}^{-1}$, respectively. Additionally, the sharp peaks of polysaccharides are attributable to $\mathrm{C}-\mathrm{O}$, 

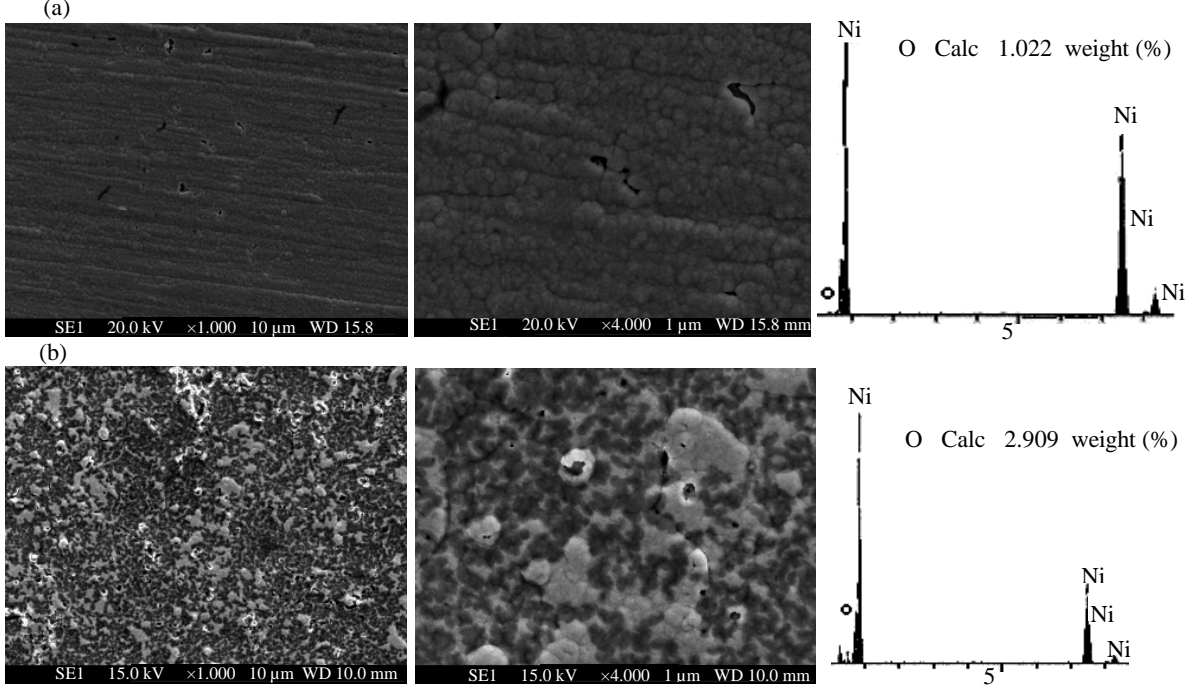

Fig. 7: EM micrographs and EDX spectrum of nickel surfaces exposed to different mediums for $5 \mathrm{~h}$ : a) sterile medium;

b) medium with bacterium

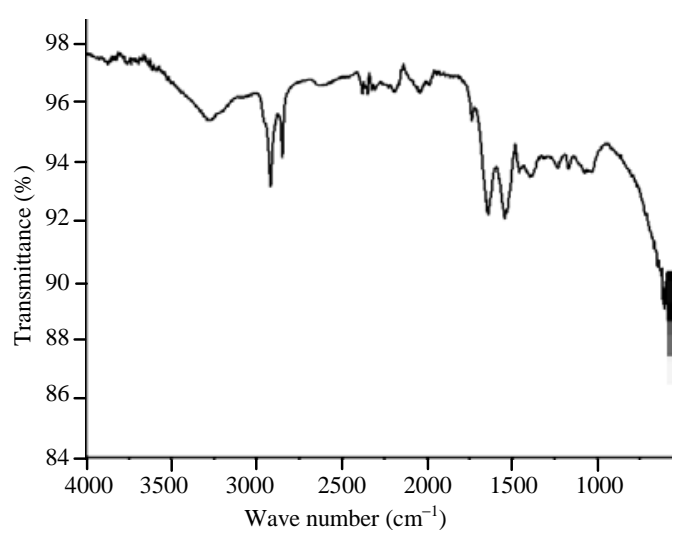

Fig. 8: FTIR spectrum of biofilm and EPS on nickel electrodes in bacterium

$\mathrm{P}=\mathrm{O}$ or $\mathrm{C}-\mathrm{O}-\mathrm{C}$, an observation which is compatible with the literature (Chan et al., 2002; Beech et al., 1999; San et al., 2011). The peaks appear at 1386, 1230 and $1072 \mathrm{~cm}^{-1}$, respectively.

From Fig. 9 in the beginning, $\mathrm{pH}$ value of nickel in the medium and the medium containing bacterium were approximately the same $(\mathrm{pH} \mathrm{7.12)}$. The $\mathrm{pH}$ value of the medium did not change throughout the exposure time however after immersion, the $\mathrm{pH}$ values decreased to $\mathrm{pH}$ 5.93 for nickel, respectively. Researchers' opinion about the decreasing of $\mathrm{pH}$ is probable due to the biofilm with EPS. EPS are primarily composed of polysaccharides, uronic acid sugars and proteins containing functional groups such as carboxylic acid and amino acid groups which could be acidic and capable of binding metal ions. Lewandowski et al. (1994) and Roe et al. (1996) found that

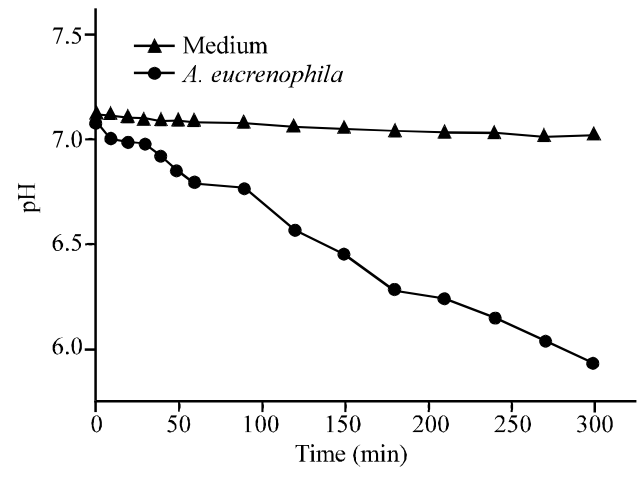

Fig. 9: $\mathrm{pH}$ changes of the medium and medium with bacterium

the biofilm $\mathrm{pH}$ at the corroded metal surface covered with EPS was in acidic area. Beech reported that with $1 \%$ EPS, the medium had a $\mathrm{pH}$ of 3.9 as compared to 6.4 in the EPS-free medium. The acidic nature is probably due to the carboxylic acid group associated with uronic acid sugars of the polysaccharides and the amino acids of the protein components of the EPS (Beech and Cheung, 1995). Thus, EPS can affect the electrochemical characteristics of metal surface and play an important role in the corrosion of metal (Fang et al., 2002). In the presence of EPS, the formation of corrosive layer of nickel may be proposed as the above reactions $(1,2)$. The inner layer maybe the nickel complex and the outer layer is mainly of EPS in case of $A$. eucrenophila:

$$
\begin{gathered}
\mathrm{mNi}+\mathrm{nH}_{2} \mathrm{O}=\mathrm{Ni}_{\mathrm{m}}^{0}\left(\mathrm{OH}^{-}\right)_{\mathrm{n}}+\mathrm{nH}^{+} \\
\mathrm{Ni}_{\mathrm{m}}^{0}\left(\mathrm{OH}^{-}\right)_{\mathrm{n}}+\left(\mathrm{n}+2 \mathrm{~m}^{2+} \mathrm{H}^{+}+\mathrm{m} / 2 \mathrm{O}_{2}=\mathrm{mNi}^{2+}+(\mathrm{n}+\mathrm{m}) \mathrm{H}_{2} \mathrm{O}\right. \\
(\mathrm{EPS}) \mathrm{x}+\mathrm{Ni}+\mathrm{H}_{2} \mathrm{O}-2 \mathrm{e}^{-} \rightarrow[(\mathrm{EPS}) \times \mathrm{NiO}]+2 \mathrm{H}^{+}(1)
\end{gathered}
$$




$$
\begin{gathered}
\mathrm{Ni} \rightarrow \mathrm{Ni}^{2+}+2 \mathrm{e}^{-} \\
1 / 2 \mathrm{O}_{2}+\mathrm{H}_{2} \mathrm{O}+2 \mathrm{e}^{-} \rightarrow 2 \mathrm{OH}^{-}(\text {cathodic }) \\
\mathrm{Ni}^{2}+(\text { EPS }) \mathrm{x}+2 \mathrm{OH}^{-} \rightarrow\left[(\mathrm{EPS}) \times \mathrm{Ni}(\mathrm{OH})_{2}\right]
\end{gathered}
$$

\section{CONCLUSION}

In this study, electrochemistry of the microbially influenced corrosion of $\mathrm{Ni}$ exposed to medium and medium containing $A$. eucrenophila were investigated. Results showed that $A$. eucrenophila attached and formed a biofilm layer on the nickel surface and the presence of possible acidic groups in the EPS increases the corrosion of nickel.

\section{ACKNOWLEDGEMENTS}

The researchers wish to thank Scientific and Technological Research Council of Turkey (TUBITAKBIDEB). Financial support was provided by TUBITAK (Project No. TBAG-106T538).

\section{REFERENCES}

Abd El-Haleem, S.M. and S. Abd El-Wanees, 2011. Chloride induced pitting corrosion of nickel in alkaline solutions and its inhibition by organic amines. Mater. Chem. Phys., 128: 418-426.

Abdallah, M. and A.Y. El-Etre, 2003. Corrosion inhibition of nickel in sulfuric acid using tween surfactants. Portugaliae Electrochim. Acta, 21 : 315-326.

Beech, I., L. Hanjagsit, M. Kalaji, A.L. Neal, V. Zinkevich, 1999. Chemical structural characterization of exopolymers produced by Pseudomonas sp. NCIMB 2021 in continuous culture. Microbiol., 145: 1491-1497.

Beech, I.B. and C.W.S. Cheung, 1995. Interactions of exopolymers produced by sulphate reducing bacteria with metal ions, Int. Biodeter. Biodegr., 35: 59-72.

Caldwell, D.E., D.R. Korber and J.R. Lawrence, 1992. Imaging of bacterial cells by fluorescence exclusion using scanning confocal laser microscopy. J. Microbiol. Method, 15: 249-261.

Cetin, D. and M.L. Aksu, 2009. Corrosion behavior of lowalloy steel in the presence of 36 Desulfotomaculum sp., Corros. Sci., 51: 1584-1588.

Chan, K.Y., L.C. Xu and H.H.P. Fang, 2002. Anaerobic electrochemical corrosion of mild steel in the presence of extracellular polymeric substances produced by a culture enriched in sulfate-reducing bacteria. Environ. Sci. Technol., 36: 1720-1727.

Costerton, J.W., Z. Lewandowski, D.E. Caldwell, D.R. Korber and H.M. Lappin-Scott, 1995. Microbial biofilms. Annu. Rev. Microbiol., 49: 711-745.
El-Taib Heakal, F., M.M. Hefny and A.M. Abd El-Tawab, 2010. Electrochemical behavior of 304L stainless steel in high saline and sulphate solutions containing alga Dunaliella salina and b-carotene. J. Alloy. Compd., 491: 636-642.

Fang, H.H.P., L.C. Xu and K. Y. Chan, 2002. Effects of toxic metals and chemicals on biofilm and biocorrosion. Water Res., 36: 4709-4716.

Franklin, M.J., D.C. White, B. Little, R. Ray and R. Pope, 2000. The role of bacteria in pit propagation of 42 carbon steel. Biofouling, 15: 13-23.

Gaylarde, C.C., 1992. Sulfate-reducing bacteria which do not induce accelerated corrosion. Int. Biodeterior. and Biodegrad., 30: 331-338.

Geesey, G.G., L. Jang, J.G. Jolley, M.R. Hankins, T. Iwaoka and P.R. Griffiths, 1988. Binding of metal ions by extracellular polymers of biofilm bacteria. Water Sci. Technol., 20: 161-165.

Hori, K. and S. Matsumoto, 2010. Bacterial adhesion: From mechanism to control. Biochem. Eng. J., 48: 424-434.

Jouen, S., M. Jean and B. Hannoyer, 2004. Atmospheric corrosion of nickel in various outdoor environments. Corrosion Sci., 46: 499-514.

Lewandowski, Z., T. Funk, F. Roe and B. Little, 1994. Spatial Distribution of $\mathrm{pH}$ at Mild Steel Surfaces using an Iridium Oxide Microelectrode. In: Microbiologically Influenced Corrosion Testing, Kearns, J.R. and B.J. Little (Eds.). ASTM STP 1232, ASTM, Philadephia, pp: 61-69.

Little, B., P. Wagner, P. Angell and D. White, 1996. Correlation between localized anodic areas and Oceanospirillum biofilms on copper. Int. Biodeterior. Biodegrad., 37: 159-162.

Little, B.J., R.I. Ray, P.A. Wagner, J. Jones Meehan, C.C. Lee and F. Mansfeld, 1999. Spatial relationships between marine bacteria and localized corrosion on polymer coated steel. Biofouling, 13: 301-321.

Roe, F.L., Z. Lewandowski and T. Funk, 1996. Simulating microbiologically influenced corrosion by depositing extracellular biopolymer on mild steel surfaces. Corrosion, 52: 744-752.

San, N.O., H. Nazir and G. Donmez, 2011. Microbial corrosion of $\mathrm{Ni}-\mathrm{Cu}$ alloys by Aeromonas eucrenophila bacterium. Corrosion Sci., 53: 221 6-2221 .

Sauerbrey, G., 1959. The use of quartz oscillators for weighing thin layers and for microweighing. Z. Phys., 155: 206-222.

Teng, F., Y.T. Guan and W.P. Zhu, 2008. Effect of biofilm on cast iron pipe corrosion in drinking water distribution system: corrosion scales characterization and microbial community structure investigation. Corrosion Sci., 50: 2816-2823.

Valcarce, M.B., S.R. de Sanchez and M. Vazquez, 2005. Localizedattack of copper and brass in tap water: The effect of Pseudomonas. Corros. Sci., 47: 795-809. 
Videla, H.A., 2001. Microbially induced corrosion: An updated overview. Int. Biodeter. Biodegrad., 48: 176-201.

Wang, W., J. Wang, H. Xu and X. Li, 2006. Electrochemical techniques used in MIC studies. Mater. Corrosion, 57: 800-804.
Yuan, S.J., M.F. Amy Choong and S.O. Pehkonen, 2007. The influence of the marine aerobic Pseudomonas strain on the corrosion of $70 / 30 \mathrm{Cu}-\mathrm{Ni}$ alloy. Corrosion Sci., 49: 4352-4385.

Zuo, R., E. Kus, F. Mansfeld and T.K. Wood, 2005. The importance of live biofilms in corrosion protection. Corrosion Sci., 47: 279-287. 